\title{
A CLASSIFICATION METHODOLOGY FOR ZERO-VOLTAGE TRANSITION PWM CONVERTERS
}

\author{
M. L. Martins, J. L. Russi and H. L. Hey \\ Power Electronics and Control Research Group - GEPOC \\ Federal University of Santa Maria - UFSM \\ 97105-900 - Santa Maria - RS - Brazil \\ mariolsm@terra.com.br, jrussi@gmail.com, hey@smail.ufsm.br - www.ufsm.br/gepoc
}

\begin{abstract}
This paper presents a classification methodology of the ZVT soft-transition technique, which is based on different ways of implementation of the auxiliary circuit voltage source. The merits and limitations of each class are presented and their key features and characteristics are discussed and experimentally analyzed on the $1 \mathrm{~kW} / 100 \mathrm{kHz}$ laboratory prototypes. By means of the proposed classification criteria, any ZVT topology can be classified, even the unpublished ones. Additionally, an overview of the main ZVT PWM converters proposed in the last decades is also presented.
\end{abstract}

KEYWORDS: DC-DC Converters, Soft-Switching.

\section{RESUMO}

Este artigo propõe uma metodologia de classificação para a técnica de comutação suave conhecida como ZVT. Esta classificação é baseada nos diferentes modos de implementação da fonte auxiliar de tensão. Os méritos e limitações de cada classe são apresentados. As particularidades e características de cada classe são discutidas e analisadas experimental-mente em protótipos de laboratório de $1 \mathrm{~kW} / 100 \mathrm{kHz}$. Por meio do critério de classificação proposto, qualquer topologia ZVT pode ser classificada, mesmo aquelas inéditas na literatura. Além disso, é apresentada uma visão geral dos principais conversores ZVT PWM propostos nas últimas décadas.

Artigo Submetido em 14/10/04

1a. Revisão em 24/01/05

Aceito sob recomendação do Ed.Assoc.Prof. José Antenor Pomilio
PALAVRAS-CHAVE: Conversores CC-CC, Comutação Suave.

\section{INTRODUCTION}

In recent years there has been a growing interest by the industry in high frequency and small size switched power converters. For this reason, an ever growing number of new topologies have been proposed in the literature. Most of them promise higher performance, efficiency and power density.

One efficacious way to obtain high efficiency converters is to employ some soft-switching technique to the power converter stage, which makes use of auxiliary components (passive and active) to limit the $d i / d t$ and/or $d v / d t$ during the commutation process and minimize the overlap between voltage and current waveforms through the switching device, thus reducing its switching losses. In some cases, the auxiliary devices shape the voltage and/or current waveforms in such way, that the current and voltage overlapping through the device is quite reduced. Although many soft-switching techniques can really improve the converter performance, the efficiency gain and benefits obtained depend on several aspects, such as switching frequency, power semiconductors device technology, power range, converter operation temperature, design methodology, etc.

The voltage-mode soft-switching methods that include all the zero-voltage switching converters (Hua et alii, 1995) and most recently zero-voltage transition converters (Hua et alii, 1991; Hua et alii, 1992) have been proving to be the most attractive soft-switching technique when the switching devices, usually majority carrier device type (for instance MOSFET), have to withstand voltages below $400 \mathrm{~V}$ (International Rectifier Application Notes). This limitation 
is a consequence of the on state resistance dependence on the device breakdown voltage, which leads to high conduction losses at high voltage devices.

The voltage mode load or switch resonant converters operate with increased current and/or voltage stresses on semiconductors. Additionally, the auxiliary inductor size, which is in series with the main power path, is proportional to the ZVS operating range of the converter. Thus, the trade-off between conduction and switching losses may neutralize the benefits, and even reduce the efficiency of a ZVS converter compared to its PWM counterpart.

The voltage-mode soft-switching method that have gained quite interest in the last years is the Zero Voltage Transition (ZVT). It is a result of its low additional conductions losses and its operation closest to the PWM converters. These remarkable features are a consequence of the ZVT auxiliary circuit location, which is placed in parallel with the main power converter. The auxiliary circuit of the ZVT converters is activate just before the main switch turn-on process to take place and ceases just after it be accomplished. This way, the additional conduction losses are quite reduced. Moreover, it has few influences in the converter operation characteristics. Due to the favorable filter current direction, during main switch turn-off process, the auxiliary circuit is kept inactive, and the commutation occurs with the aid of a simple capacitive snubber placed across main switch or main diode.

The ZVT technique was firstly presented in (Hua et alii, 1991). After a couple of months, Hua and Lee presented a homonymous paper with a modified topology (Hua et alii, 1992) that would be historically considered as the conventional ZVT circuit. In spite of the promising characteristics and simplicity, the topology proposed in (Hua et alii, 1992) presents inadequate auxiliary switching conditions that have driven the engineers and researchers to present a sort of circuit variations aiming to overcome the problems related to the auxiliary switching conditions. A result of this situation is a decade plenty of promising novel ZVT topologies that, in most cases, insert several auxiliary components to solve partially a small problem, introducing additional restrictions and disadvantages (Bazinet and O’Connor, 1994; Tseng and Chen, 1998; Kim et alii, 1998; Menegáz et alii, 1999; Kim et alii, 2001; Jain et alii, 2001).

Intending to provide a concise analysis about the ZVT softswitching technique and further, gather the similar ZVT PWM converters into groups, this paper proposes a novel classification method, which separates these converters according to the way that the auxiliary voltage source, required for the proper operation of the converter, is implemented.

This paper is organized as follows: Section 2 presents the ZVT PWM converters operation mechanism. Section 3 introduces the classification of these converters, as well as the classification criteria and the description of each one of the classes generated. Finally, Section 4 presents a summary of the features of each class and the main benefits that the classification methodology can bring up.

\section{ZVT PWM CONVERTERS MECHANISM}

To obtain a better understanding about the ZVT PWM mechanism it is necessary to define a basic PWM block, from which the general analysis is carried out. The basic PWM block is comprised of a single-pole, double-throw switch, which controls the energy flow from the source to the load; and of energy storage/transfer elements, usually inductors and capacitors (Irie, 1991). One of the switch terminals is connected to the pole and the other switches from one to other of the throw terminals, Fig 1(a). As the current flowing through an inductor or a current source must always have a path to flow (Liu and Lee, 1988), it has to be connected to the pole of the switch. On the other hand, a capacitor or a voltage source must never be shorted, hence, it may not be connected between the pole and other terminal (Liu and Lee, 1988). This way, the energy storage elements, represented by a current and a voltage source, I and V, respectively, are placed as shown Fig 1(b).

In DC-DC single-ended PWM converter, the PWM switch is implemented by means of an uncontrolled switch and a controlled switch, implemented by semiconductor devices, such as BJTs, IGBTs, MOSFETs, etc. The simplified PWM block is shown in Fig. 1(c). Due to the presence of static and dynamic imperfections and further finite switching times in the semiconductor devices, the commutation process is not ideally lossless. Actually, both current and voltage are present through/on the semiconductor during its turn-on and turn-off. There are some important reasons to limit the current and voltage overlap during the switch transition between on and off states. One of these requirements is to keep the switching trajectories in the Safe Operation Area (SOA) of the device. Another reason is to limit the power dissipation in the device due to the switching losses, which are proportional to the switching trajectories and to the converter switching frequency.

In a zero voltage mode commutation process, some outside circuitry must keep the voltage across the switch at, or very

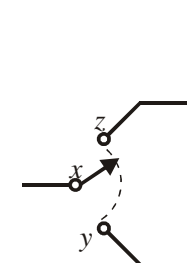

(a)

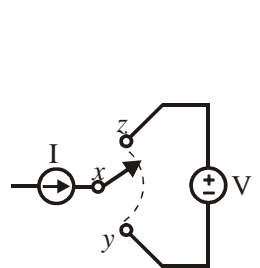

(b)

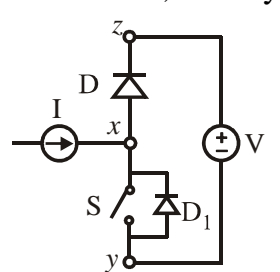

(c)
Fig. 1 - Diagrams of the Basic PWM Block. 
close to, zero, until the semiconductor to be completely turned on. In ZVT converters (Hua et alii, 1991; Hua et alii, 1992; Prado, 1994; Filho et alii, 1994; Tseng and Chen, 1998), the turn-on process under ZVS is accomplished ensuring the conduction of the switch body-diode. Therefore, the auxiliary circuit must drive smoothly the voltage across the body-diode of the switch to zero and, hereafter, force current to flow through it. To realize such task an auxiliary path must be introduced to divert the current I from main diode to it. This way, the auxiliary circuit can be viewed as a controlled current source (Vlatkovic and Borojevic, 1994; Smith and Smedley, 1997) and a snubber capacitor placed across the switch terminals, Fig 2(a). In practical applications, the controlled current source $i_{\mathrm{a}}$ can be emulated by an inductor $\mathrm{L}_{\mathrm{a}}$ in series with a controlled voltage source $v_{t y}$, as shown in the shaded area of Fig 2(b). Considering that the voltage at the terminal $x\left(v_{x y}\right)$ is a function of the PWM switching elements, Fig. 2(b), the circuit can be simplified as shown in Fig. 3(a). Moreover, as the current source $I$ is virtually in parallel with the controlled voltage source $v_{x y}$, the circuit can be further simplified as shown in Fig. 3(b) (Liu and Lee, 1988).

The voltage waveforms of the controlled voltage source $v_{\mathrm{xy}}$ are shown in Fig. 4. In order to control the current through auxiliary inductor $L_{a}$ in such way that it would emulate the controlled current source of Fig. 2(a), the controlled voltage source $v_{\text {ty }}$ (Fig. 3(b)) must observe the following inequalities,

$$
\begin{aligned}
& \left.V_{t y}\right|_{t<t_{1}}<V_{x y} \\
& \left.V_{t y}\right|_{t>t_{2}}>V_{x y}
\end{aligned}
$$

In practical applications, the controlled voltage source $v_{\text {ty }}$ is emulated by a set of elements that can include passive and active semiconductor devices, inductor(s), capacitor(s), transformer(s), etc. For this reason, the elements that

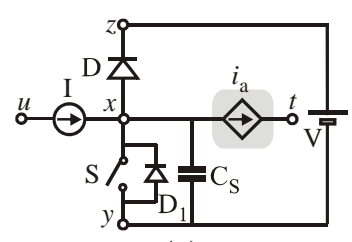

(a)

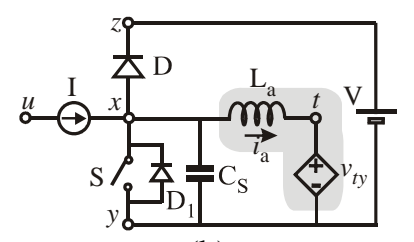

(b)
Fig. 2 - Auxiliary Circuit Representations. (a) Controlled Current Source; (b) Inductor in Series Connection with Controlled Voltage Source.

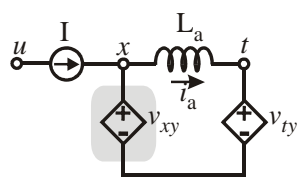

(a)

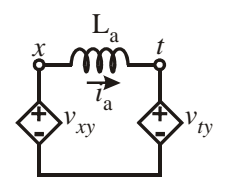

(b)
Fig. 3 - Basic PWM Block and Auxiliary Circuit Representations.

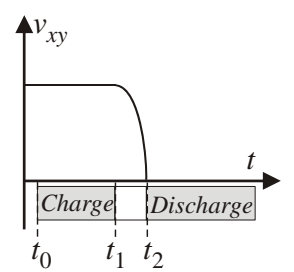

Fig. 4 - Waveforms of the Controlled Voltage Source $v_{x y}$.

constitute the controlled voltage source $v_{\text {ty }}$ will be referred hereafter as Auxiliary Voltage Source - AVS.

\section{CLASSIFICATION OF ZVT PWM CONVERTERS.}

In spite of the plentiful number of ZVT PWM converters, they can be gathered in three classes, which have as main difference the means that the AVS is implemented. Moreover, each AVS implementation holds some features that distinguish the classes from each other.

The ideal theoretical waveforms $v_{\mathrm{xy}}$ and $v_{\text {ty }}$ and corresponding auxiliary circuit current, $i_{a}$, for each one of the three groups or classes, are shown in Fig. 5. In Fig. 5(a), the voltage applied across inductor $\mathrm{L}_{\mathrm{a}}$ during its charge $\left(\mathrm{t}_{0}<\mathrm{t}<\mathrm{t}_{1}\right)$ and discharge $\left(\mathrm{t}_{2}<\mathrm{t}<\mathrm{t}_{3}\right)$ periods assumes two different constant values and between these two intervals there is a short resonant mode $\left(t_{1}<t<t_{2}\right)$. Thus, low reactive energy is ensured. In a general form, the inductor charge depends on voltage source $v_{\mathrm{xy}}$, while the discharge depends

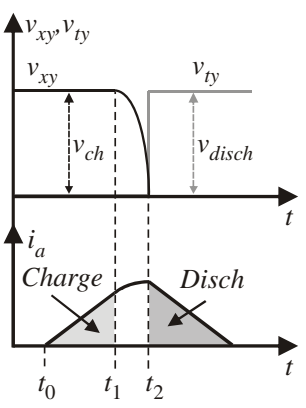

(a)

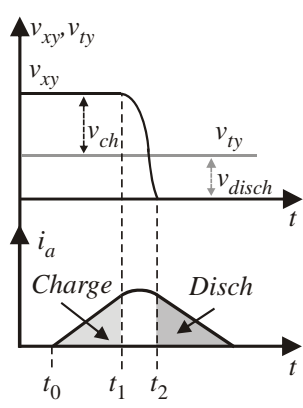

(b)

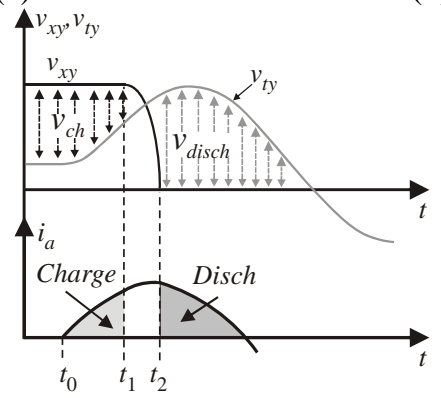

(c)

Fig. 5 - Waveforms of the Controlled Voltage Source $v_{x y}$, $\mathrm{V}_{\text {ty }}$ and Corresponding Auxiliary Circuit Current $\mathrm{I}_{\mathrm{a}}$.

(a) For a $v_{\text {ty }}$ Discontinuous Function; (b) For a $v_{\text {ty }}$ Constant Function; (c) For a $v_{\text {ty }}$ Continuous Time Variant Function. 
on voltage source $v_{\text {ty }}$, characterizing two independent processes. The ZVT converters that employ this mechanism to realize the AVS are gathered into a group referred as Class A - ZVT PWM converters with Switched AVS, whose characteristics will be addressed in sub-section 3.1.

In Fig. 5(b) the constant voltage source $v_{\text {ty }}$ also ensures low reactive energy. However, the inductor charge depends on both voltage sources $v_{\mathrm{xy}}$ and $v_{\mathrm{ty}}$, while the discharge depends just on voltage source $v_{\mathrm{ty}}$, characterizing the dependence between the charge and discharge processes. To ensure ZVS turn-on, $v_{\text {ty }}$ must be a constant value between zero and $0.5 V_{\text {xy(MAX) }}$ (Russi et alii, 2003). Thus, the voltages applied across $\mathrm{L}_{\mathrm{a}}$ to charge and discharge it are smaller, leading to longer charging and discharging periods. The ZVT converters that employ this mechanism to realize the AVS are gathered into a group referred as Class $B-$ ZVT PWM converters with DC AVS, whose characteristics will be addressed in sub-section 3.2.

In a different way, Fig. 5(c) presents a voltage source $v_{\text {ty }}$ that assumes a sinusoidal waveform producing a large amount of reactive energy. Moreover, the commutation interval depends on the frequency of the mentioned sinusoidal waveform. The ZVT converters that employ this mechanism to realize the AVS are gathered into a group referred as Class $C-Z V T$ PWM converters with Resonant $A V S$, whose characteristics will be addressed in sub-section 3.3.

\subsection{Class A - ZVT PWM converters with Switched AVS}

In a general form, the ZVT converters with switched AVS provide an AVS that switches the voltage across the auxiliary inductor between two values that are represented as $\mathrm{V}_{\mathrm{A} 1}$ and $\mathrm{V}_{\mathrm{A} 2}$ in Fig. 6(a).

The current stress is inversely proportional to the value of $\mathrm{V}_{\mathrm{A} 1}$ while the commutation interval is directly proportional to the value of $\mathrm{V}_{\mathrm{A} 1}$ and inversely proportional to $\mathrm{V}_{\mathrm{A} 2}$.

Even knowing the trade-offs mentioned before, engineer designers usually choose the switched AVS shown in Fig. $6(\mathrm{~b})$, where the voltage source $\mathrm{V}_{\mathrm{A} 1}$ is zero and $\mathrm{V}_{\mathrm{A} 2}$ is the voltage across terminals $z$ and $y$. This choice avoids extra complexity due to the design of the values of $\mathrm{V}_{\mathrm{A} 1}$ and $\mathrm{V}_{\mathrm{A} 2}$, although, disregards the trade-offs among $\mathrm{I}_{\mathrm{La}(\mathrm{MAX})}, \Delta_{\mathrm{tC}}$ and $\mathrm{W}_{\text {Loss. }}$.

For the simplified AVS, the Class A of ZVT converters can be further split in two sub-classes, according to the mechanism used to alleviate the auxiliary circuit switching losses. The sub-classes are ZVT PWM converters with switched AVS snubber assisted and ZVT PWM converters with self-commutated switched AVS. In these converters the current stress on the auxiliary circuit is, usually, a function determined only by the characteristic impedance of the resonant circuit. The resonant interval is always equal to $1 / 4$ of the resonant period. Thus, the circulating reactive energy due to the action of the auxiliary circuit is independent on the value of $\mathrm{V}_{\mathrm{A} 2}$, which is only responsible for the discharge of $\mathrm{L}_{\mathrm{a}}$.

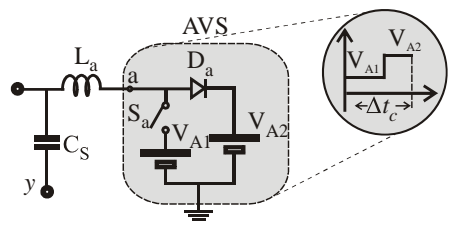

(a)

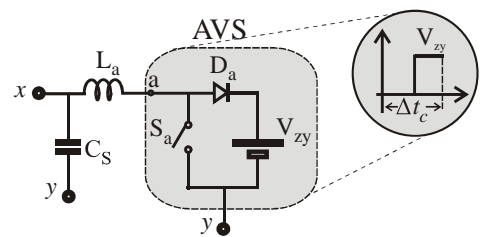

(b)

Fig. 6 - Diagrams of the Basic ZVT Class A Circuit. (a) Complete; (b) Simplified.

It can be seen that the diagram of the switched AVS structure shown in Fig. 6(b) resembles the basic PWM block, this way it can also be viewed as an auxiliary boost converter operating in discontinuous conduction mode, DCM. This DCM operation of the auxiliary circuit alleviates the turn-on losses that are reduced to only the losses related to the discharge of the energy stored in the device parasitic capacitances (turn-on capacitive losses). However, the turn-off losses are the same as in the hard switched PWM converter. For this reason, the auxiliary pole comprised by the switch $\mathrm{S}_{\mathrm{a}}$ and diode $\mathrm{D}_{\mathrm{a}}$ will experiment the turn-off losses related to the overlap between the voltage and current waveforms, as in the hard switched PWM converters. These problems are related to the implementation of the switching device, which can be either of the majority carriers device type (e.g., MOSFET) or of the minority carriers device type (e.g., IGBT).

To minimize this drawback, usually passive soft-switching techniques are employed. These techniques are based on the snubber action of a capacitive element (Kim et alii, 1998; Menegáz et alii, 1999; Kim et alii, 2001; Streit and Tollik, 1991; Yaakov et alii, 1995; Liu et alii, 2000; Kim et alii, 2000; Bodur and Bakan, 2002), Fig. 7, termed ZVT PWM converters with switched AVS snubber assisted, or in the action of a resonant tank added to the auxiliary circuit (Martins et alii, 2001; Martins et alii, 2002; Gurunathan and Bhat, 2001) Fig. 8, termed ZVT PWM converters with self-commutated switched AVS. 
Although ZVT PWM converters with switched AVS snubber assisted alleviate the turn-off losses, it cannot avoid the turn-on capacitive losses and the commutation conditions still being ZCS turn-on and ZVS turn-off, which keeps the switching losses quite dependent on the device technology used as auxiliary switch. Some topologies can further improve the efficiency by reducing the conduction losses of auxiliary circuit. This characteristic is obtained by choosing the location of the snubber capacitor of auxiliary switch in such a way that it can also limit the voltage rise rate across main switch during its turn-off process (Streit and Tollik, 1991; Yaakov et alii, 1995; Liu et alii, 2000; Kim et alii, 2000; Bodur and Bakan, 2002), Fig. 7(c) and 7(d). This approach is known as flying capacitor.

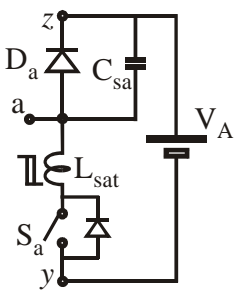

(a)

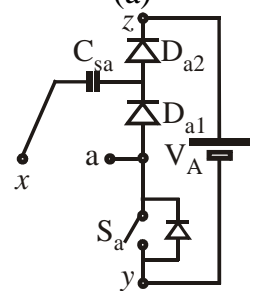

(c)

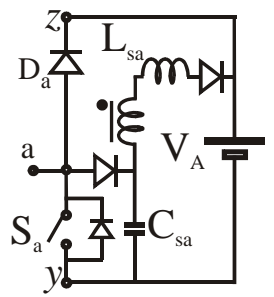

(b)

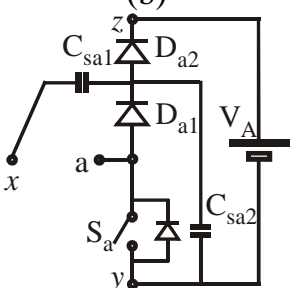

(d)
Fig. 7 - Snubber Assisted Auxiliary Switch ZVT Circuits.

(a) (Kim et alii, 2001); (b) (Menegáz et alii, 1999); (c)

(Streit and Tollik, 1991; Yaakov et alii, 1995; Bodur and Bakan, 2002); (d) (Kim et alii, 2000).

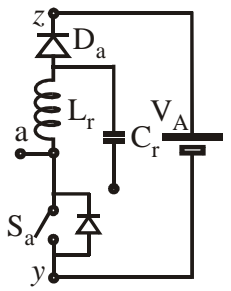

(a)

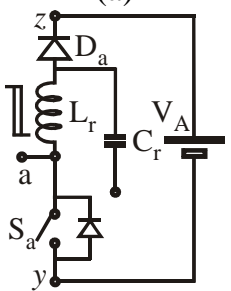

(c)

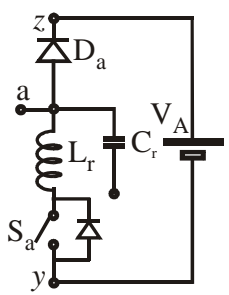

(b)

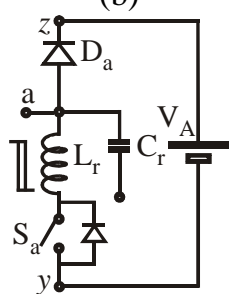

(d)
Fig. 8 - Self-Commutated Auxiliary Switch ZVT Circuits. (a) (Martins et alii, 2001); (b) (Martins et alii, 2002); (c) Unpublished; (d) Unpublished.
In the case of ZVT PWM converters with self-commutated switched AVS, the auxiliary switch turn-off losses are minimized employing an auxiliary circuit which is very similar to the well known resonant switch converters or quasi-resonant converters-QRC (Lee et alii, 1985), Fig. 8(a) and 8(b). Due to the DCM operation of the auxiliary circuit, it is required that the static-point of the resonant circuit occurs when the auxiliary switch is in the off state. Thus, the resonant switch must be of the QRC-ZCS-FM type only. A consequence of this is the fact that the parasitic capacitances are also not absorbed; however, the ZCS conditions are more suited to minority carrier devices type, which have lower losses related to their smaller parasitic output capacitance.

It can be noticed that some of the various modifications presented in the literature to improve the performance of QRC converters can be also applied to the ZVT PWM converters with self-commutated Switched AVS, such as non-linear resonant inductor (Erickson et alii, 1989), Fig 8(c,d) and inclusion of a DC voltage in series with the resonant circuit (Ba-Thunya et alii, 1998) without (Fig. 9(a,b)) and with (Fig. 9(c,d)) clamping diode.

Fig. 10 shows the experimental waveforms of the auxiliary elements for three ZVT boost converters. The specifications of the prototypes are as follows: $\mathrm{f}_{\mathrm{s}}=100 \mathrm{kHz}, \mathrm{V}_{\mathrm{i}}=150 \mathrm{~V}_{\mathrm{DC}}$, $\mathrm{V}_{\mathrm{o}}=400 \mathrm{~V}_{\mathrm{DC}}, \mathrm{P}_{\mathrm{o}}=1 \mathrm{~kW}$. For the results shown in Fig. 10(a) and (b) the auxiliary switches of prototypes were the IRF840 (MOSFET). For Fig. 10(c), the prototype auxiliary switch is the HGTP7N60C3D (IGBT).

Fig 10(a) shows the waveforms for the conventional ZVT boost converter (Hua et alii, 1992), where it can be seen that the voltage across the auxiliary switch presents a high

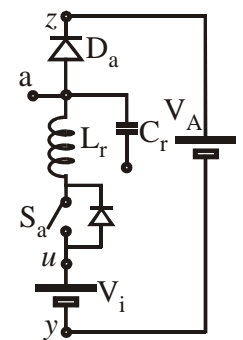

(a)

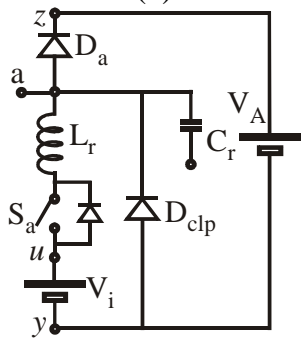

(c)

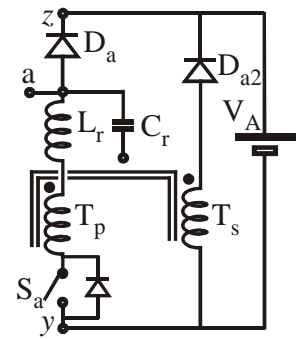

(b)

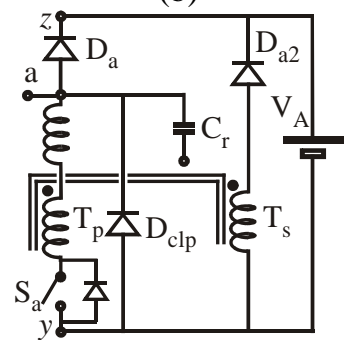

(d)
Fig. 9 - Modified Self-Commutated Auxiliary Switch ZVT circuits. 
$d v / d t$ during its turn-off. Fig. 10(b) shows the same waveforms of Fig. 10(a) for the ZVT boost auxiliary switch snubber assisted converter (Streit and Tollik, 1991). It can be seen that the auxiliary switch presents a limited $\mathrm{dv} / \mathrm{dt}$ during its turn-off, which reduces the voltage and current overlapping, improving the converter efficiency. Fig. 10(c) shows the waveforms of the ZVT boost converter with parallel self-commutated auxiliary circuit (Martins et alii, 2002), which presents an auxiliary switch that commutates with ZCS conditions. It can be seen that the auxiliary switch $d v / d t$ in both Fig. 10(b) and 10(c) are reduced compared to Fig. 10(a). Additionally, the ZCS conditions allows the employment of a IGBT device, which in turn, minimize the turn-on capacitive losses presented by the MOSFET devices used in the prototypes of the ZVT boost converter (Hua et alii, 1992) and the ZVT boost auxiliary switch snubber assisted converter (Streit and Tollik, 1991). Nevertheless, the ZCS auxiliary switch presents a huge current spike after its anti-parallel diode turn-off, increasing the voltage and current overlapping and thus, partially counteract the gains obtained by the reduction in capacitive losses.

\subsection{Class B - ZVT PWM converters with DC AVS}

In order to direct the power back to the main circuit after the turn-on of the main switch, the ZVT converters with DC AVS employ a simple DC voltage source in series connection with the inductor $\mathrm{L}_{\mathrm{a}}$, Fig. 11, (Freitas et alii, 1993; Filho et alii, 1994; Prado, 1994; Martins et alii, $1993 ; . .$.$) .$

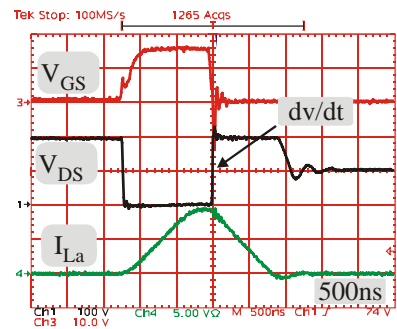

(a)

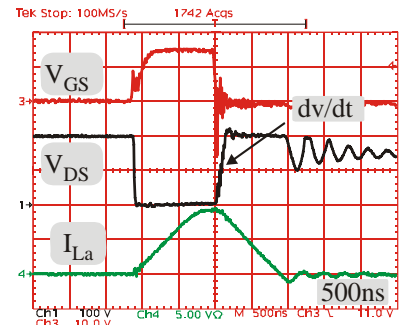

(b)

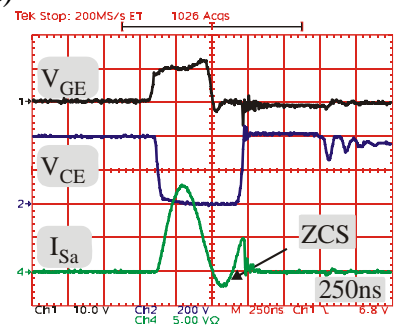

(c)

Fig. 10 - Experimental Waveforms for the Auxiliary Elements. (a) (Hua et alii, 1992); (b) (Streit and Tollik, 1991); (c) (Martins et alii, 2002). $\mathrm{V}_{\mathrm{GS}}, \mathrm{V}_{\mathrm{GE}}-10 \mathrm{~V} / \mathrm{div}$.; $\mathrm{V}_{\mathrm{DS}}, \mathrm{V}_{\mathrm{CE}}-200 \mathrm{~V} /$ div.; $\mathrm{I}_{\mathrm{La}}$, $\mathrm{I}_{\mathrm{Sa}}-5 \mathrm{~A} /$ div.
The Class B of ZVT converters can be split in two subgroups, according to the implementation of the DC voltage source. Thus, it can be divided in two sub-classes, the ZVT PWM converters with DC AVS and the ZVT PWM converters with magnetically coupled DC AVS. The basic circuit of these sub-classes of ZVT converters is shown in Fig. 12.

Besides the inclusion of this DC voltage source to allow the control of the power flow between main and auxiliary circuits, it also brings other benefits as, (i) ZCS switching conditions to the auxiliary switch; and, (ii) reduction of auxiliary circuit current and voltage stresses. This last feature is a consequence of the location of voltage source $\mathrm{V}_{\mathrm{A}}$ that is always in series connection with inductor $\mathrm{L}_{\mathrm{a}}$ and auxiliary switch $S_{a}$. Therefore, the choice of the values to be assumed by $\mathrm{V}_{\mathrm{A}}$ has influence in the resonant process and it can be used to minimize the current stress through the auxiliary circuit and further reduce the reactive energy produced by the action of the auxiliary circuit. Although the value of $\mathrm{V}_{\mathrm{A}}$ can vary in order to reduce stresses and energy on the auxiliary circuit, it is limited by the soft-switching conditions of main switch, i. e., the value of $V_{A}$ must be within a defined range to ensure the soft-switching conditions of the converter (Russi et alii, 2003). Additionally, $\mathrm{V}_{\mathrm{A}}$ also has influence on the commutation interval. The implementation of the auxiliary DC voltage source can be made by means of an outside voltage source (Freitas et alii, 1993), an existing converter voltage source or sink (Filho et alii, 1994; Prado, 1994), or even a magnetically coupled voltage source (Martins et alii, 1993; Gegner and Lee, 1994a; Gegner and Lee, 1994b; Lee et alii, 1998; Lee et alii, 2002; Hey et alii, 1996). Each one of the implementation techniques presents advantages and drawbacks, which are described below:

- In some applications it is difficult to obtain an additional DC voltage source, which almost always results in an increase in converter volume (Freitas et alii, 1993);

- As $\mathrm{V}_{\mathrm{A}}$ is limited for a range of values, using a

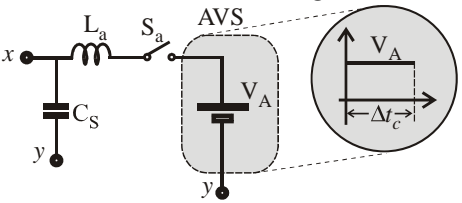

Fig. 11 - Diagram of the Basic ZVT Class B Circuit.

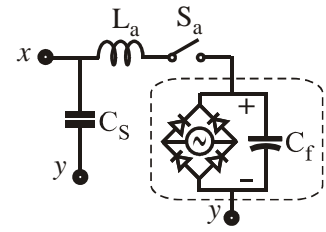

(a)

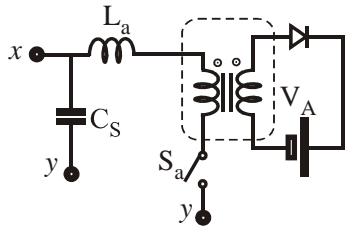

(b)
Fig. 12 - Diagrams of the Different Implementations of the DC Voltage Source. (a) DC Source; (b) Magnetic Coupling. 
converter voltage source or sink leads to operation under limited voltage ratio conversion that may further constrain the utilization of these topologies or even implies in higher voltage ratings for the components, which normally increases their internal resistances or voltage drops resulting in greater conduction losses, (Filho et alii, 1994) and (Martins et alii, 1993);

- The voltage transformers are often subjected to demagnetizing problems resulting in EMI degradation and an increase in converter volume and complexity, (Martins et alii, 1993; Gegner and Lee, 1994b; Lee et alii, 2002);

Based on the above mentioned, the two sub-groups, the ZVT PWM converters with DC AVS and the ZVT PWM converters with magnetically coupled DC AVS are clearly identified. The different implementations of the ZVT PWM converters with magnetically coupled DC AVS are shown in Fig. 13. Choosing the values of the voltage sources $V_{P}, V_{Q}$ and $\mathrm{V}_{\mathrm{R}}$ it will result in different ZVT PWM converters with magnetically coupled DC AVS topologies, where some of them are known in the literature and the others are unpublished yet. Indeed, in a general way, the published converters present the voltage source $V_{R}$ and $V_{Q}$ equal to the voltage $V_{z y}$, and $V_{P}$ equal zero. The range of the valid values of the voltage sources $\mathrm{V}_{\mathrm{P}}, \mathrm{V}_{\mathrm{Q}}$ and $\mathrm{V}_{\mathrm{R}}$ are shown in Table 1.

As a result of the ZCS of the auxiliary switch, minority carrier devices can be used minimizing auxiliary switch turn-on capacitive losses verified in the ZVT converters with DC AVS - Class B.

Other advantage presented by ZVT converters with DC AVS is that the auxiliary DC source also can be used to reduce the stresses on the auxiliary circuit, which are no longer solely dependent on the resonant snubber elements $\mathrm{L}_{\mathrm{a}}-\mathrm{C}_{\mathrm{s}}$.

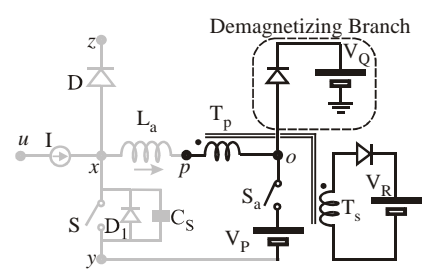

(a)

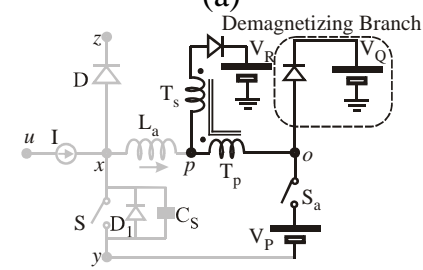

(c)

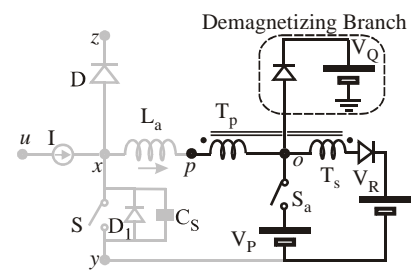

(b)

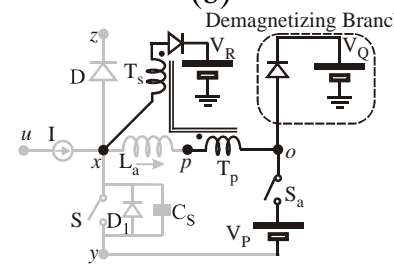

(d)
Fig. 13 - Diagrams of the Different Configurations of the Magnetic Coupled DC Voltage Source.
Table 1 - Voltage source constraints

\begin{tabular}{c|c|c}
\hline Voltage Source & Transformer Windings & Condition \\
\hline$V_{\mathrm{P}}$ & $\begin{array}{c}\text { Non-isolated } \\
\text { Isolated }\end{array}$ & $\mathrm{V}_{\mathrm{P}}<\mathrm{V}_{z y}$ \\
\hline \multirow{2}{*}{$\mathrm{V}_{\mathrm{Q}}$} & Non-isolated & $\mathrm{V}_{\mathrm{Q}} \geq \mathrm{V}_{z y}$ \\
\cline { 2 - 3 } & Isolated & $\mathrm{V}_{\mathrm{R}} \geq \mathrm{V}_{\mathrm{ZY}}$ \\
\multirow{2}{*}{$\mathrm{V}_{\mathrm{R}}$} & Non-isolated & $\mathrm{V}_{\mathrm{R}} \geq \mathrm{V}_{\mathrm{P}}$ \\
\cline { 2 - 3 } & Isolated & $\mathrm{V}_{\mathrm{R}} \geq 0$ \\
\hline
\end{tabular}

The power stages shown in Fig. 14 (a) (Martins et alii, 1993), (b) (Martins et alii, 1993), (c) (Lee et alii, 2002; Hey et alii, 1996), and (d) (Gegner and Lee, 1994b) are derived from diagrams of Fig. 13 (a), (b) (c) and (d), respectively. These power stage circuits operate at $1 \mathrm{~kW} / 100 \mathrm{kHz}$ from a constant input voltage $\mathrm{V}_{\mathrm{i}}=150 \mathrm{~V}_{\mathrm{DC}}$ and supply a resistive load $\left(\mathrm{V}_{\mathrm{o}}=400 \mathrm{~V}_{\mathrm{DC}}\right)$. The auxiliary circuit elements consist of a $16 \mu \mathrm{H}$ resonant inductor $\mathrm{L}_{\mathrm{a}}$, a $2.2 \mathrm{nF}$ snubber capacitor $\mathrm{C}_{\mathrm{s}}$ and a two-winding transformer placed as shown in Fig. 14(a), (b), (c) and (d). The different configurations result in different current stresses and RMS values through the

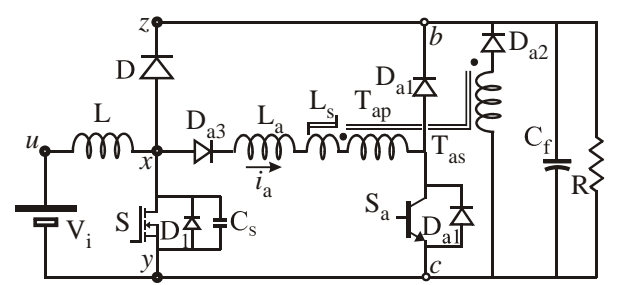

(a)

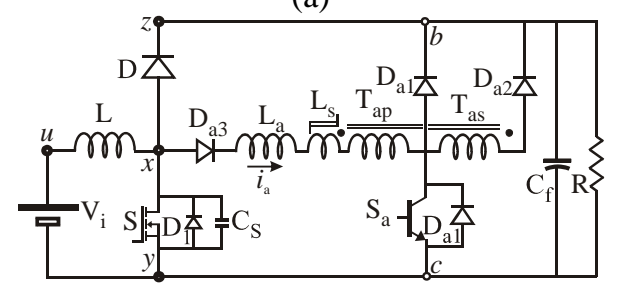

(c)

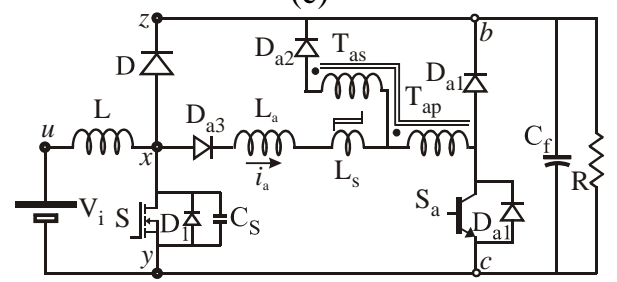

(b)

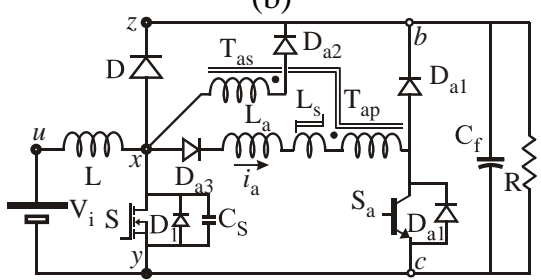

(d)

Fig. 14 - Topologies of the Converters Evaluated. (a) (Martins et alii, 1993); (b) (Martins et alii, 1993);

(c) (Lee et alii, 2002; Hey et alii, 1996); and

(d) (Gegner and Lee, 1994b). 
auxiliary circuit elements. Fig. 15 presents the current waveforms for four ZVT PWM boost converters employing the different configurations for the magnetically coupled DC AVS. It can be seen that with configuration of Fig. 14(a) (Martins et alii, 1993) the transformer primary winding $\left(\mathrm{T}_{\mathrm{P}}\right)$, auxiliary inductor $\left(\mathrm{L}_{\mathrm{a}}\right)$ and auxiliary switch $\left(\mathrm{S}_{\mathrm{a}}\right)$ must withstand the highest current stress - Fig. 15(a). For the configuration of Fig. 14(b) (Martins et alii, 1993), current through $S_{a}$ is smaller - Fig. 15(b), meanwhile for the configuration of Fig. 14(c) (Lee et alii, 2002; Hey et alii, 1996), only the auxiliary inductor must withstand the higher current stress - Fig. 15(c). It also can be seen (Fig. 15(d)) that configuration of Fig. 14(d) (Gegner and Lee, 1994b) provides the smallest stresses and RMS current values for the auxiliary circuit elements, which is a result of the direct connection of the parallel path formed by the transformer windings to the terminal $x$ of the PWM basic block.

\subsection{Class C - ZVT PWM converters with Resonant AVS}

To achieve the auxiliary switch ZCS conditions, likewise the converters of class $\mathrm{B}$, the ZVT converters with resonant AVS - class C, replace the DC voltage source, which presents some practical implementation problems by a resonant tank $\left(\mathrm{L}_{\mathrm{r}}\right.$ and $\mathrm{C}_{\mathrm{r}}$ ) (Yang and Lee, 1993; Xu et alii, 2000; Moschopoulos et alii, 1995; Moschopoulos et alii, 1996; Tseng and Chen, 1998; Jain et alii, 2001), Fig. 16(a). The resonant tank provides a resonant process that forces the voltage and current through the inductor $L_{a}$ to assume a sinusoidal shape. This approach is a very simple way to implement the AVS without the need of any constant

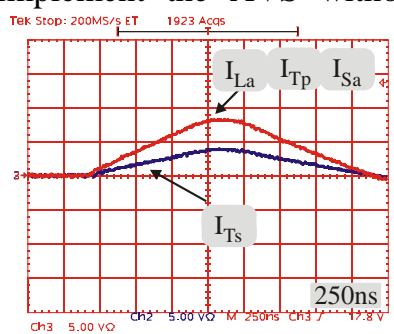

(a)

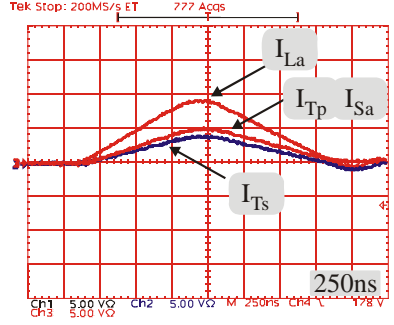

(c)

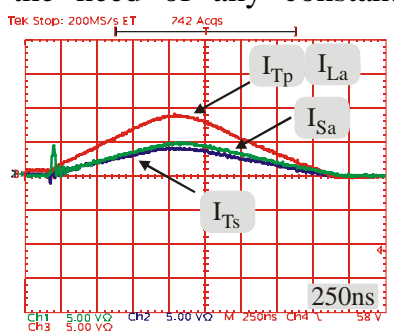

(b)

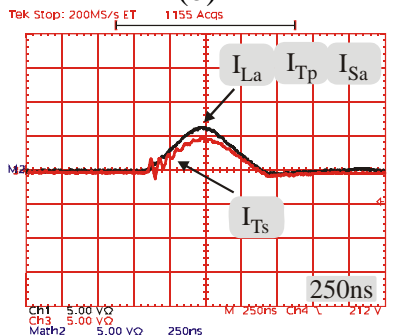

(d)
Fig. 15 - Experimental Waveforms for the Auxiliary Elements. (a) (Martins et alii, 1993); (b) (Martins et alii, 1993); (c) (Lee et alii, 2002; Hey et alii, 1996); (d) (Gegner and Lee, 1994b). $\mathrm{I}_{\mathrm{La}}, \mathrm{I}_{\mathrm{Ts}}$, $\mathrm{I}_{\mathrm{Tp}}, \mathrm{I}_{\mathrm{Sa}}-5 \mathrm{~A} /$ div.; Time 250 ns/div. voltage source. During the 60's, it was used in several SCR applications as a forced commutation circuit (McMurray, 1964).

As $\mathrm{L}_{\mathrm{a}}$ and the resonant circuit inductor are connected in series, they can be gathered into one inductor, Fig 16(b). Another circuit characteristic is that the terminal $w$ can appear connected to different terminals of the main PWM block, i. e. the voltage $V_{w}$ can be zero, or assume the voltage of any other constant potential.

This Class can be divided into two sub-groups, the $Z V T$ $P W M$ converters with Resonant AVS and the ZVT PWM converters with Resonant AVS and Clamping Circuit.

Although ZCS conditions are ensured to the auxiliary switch commutations, the circuit shown in Fig. 16(b) presents some drawbacks as, (i) the main switch, which is connected between terminals $x$ and $y$, suffers with the current spike during the turn-on process; (ii) the voltage boosting of capacitor $\mathrm{C}_{\mathrm{r}}$; and, (iii) the extra degree of analysis and design complexity characterized by a third order state variable resonant system.

The first and second drawbacks mentioned above are partially minimized by the manipulation and/or the inclusion of additional elements in the auxiliary circuit.

Among the topological variations of the auxiliary circuit, it can be seen that two different tendencies are observed. One of these tendencies, named by ZVT PWM converters with Resonant AVS and clamping circuit, is the inclusion of elements that clamp the voltage across $C_{r}$ at some value and thus, avoid the inherent voltage boosting (Hua et alii, 1991), (Yang and Lee, 1993) and (Xu et alii, 2000). In contrast, other topologies adopt some apparatus that offset the voltage boosting (Moschopoulos et alii, 1995; Moschopoulos et alii, 1996; Tseng and Chen, 1998; Jain et alii 2001).

Based on the above mentioned, the two sub-classes, the ZVT PWM converters with Resonant AVS and the ZVT

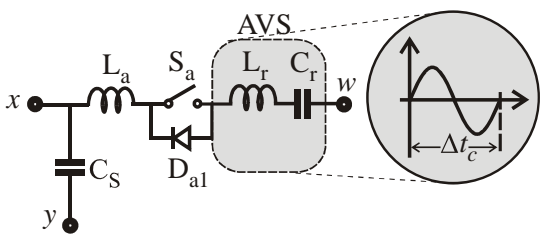

(a)

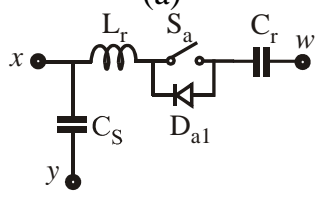

(b)

Fig. 16 - Diagrams of the Basic ZVT Class C Circuit. (a) Complete; (b) Simplified. 
PWM converters with Resonant AVS and Clamping Circuit are clearly identified. The basic circuit of these sub-classes of ZVT converters is shown in Fig. 17, where the configurations of Fig. 17(a) and 17(b) do not use clamping circuit and configuration 17(c) uses a clamping circuit.

As it happens in Class B, the auxiliary switch commutates with ZCS conditions, which enables the use of minority carrier devices alleviating considerably the turn-on capacitive losses. Other characteristic retained from Class B is that the current stress through the auxiliary circuit can be made smaller than that presented by Class A, however, it has a different impact over the reactive energy which is strongly dependent on the characteristic impedance of the resonant tank and is normally enlarged by the addition of a third resonant element. One of the important drawbacks presented by the converters of the Class $\mathrm{C}$ is the over current imposed to the main switch during its turn-on process.

As an example, Fig. 18 shows the experimental waveforms obtained from three different Class C ZVT PWM boost converters. In Fig. 18(a) it can be seen the main switch turn-on waveforms for the ZVT PWM converter with Resonant AVS presented in (Tseng and Chen, 1998; Smith and Smedley, 1997), where the over current through main switch, which is common in all converters of the Class $\mathrm{C}$, can be verified. Fig. 18(b) shows the waveforms of the resonant tank elements, current through resonant inductor $L_{r}$ and voltage across resonant capacitor $C_{r}$. It can be seen that the resonant process lasts until the current through $\mathrm{L}_{\mathrm{r}}$ reaches zero, confirming that no clamping occurs, characterizing the ZVT PWM converter with Resonant AVS sub-Class. On the other hand, Fig. 18(c) shows the waveforms of the resonant tank elements (current through $\mathrm{L}_{\mathrm{r}}$ and voltage across $\mathrm{C}_{\mathrm{r}}$ ) for the ZVT PWM Converters with Resonant AVS and Clamping Circuit presented in (Xu et alii, 2000). The clamping circuit action takes place soon after the voltage across the resonant capacitor reaches its

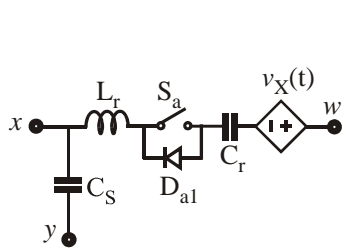

(a)

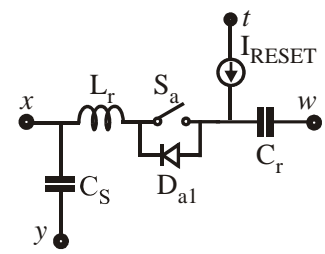

(b)

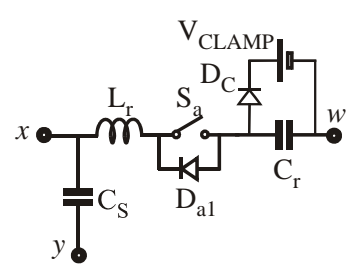

(c)

Fig. 17 - Diagrams of the Different Configurations to Offset the Voltage Boosting Characteristics.

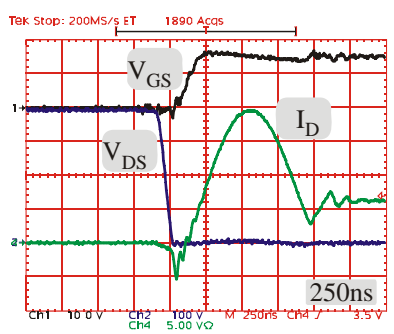

(a)

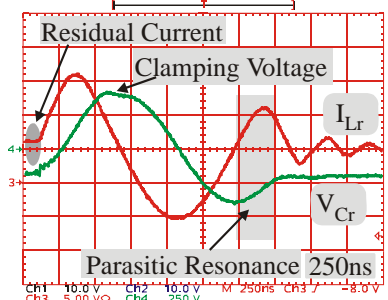

(c)

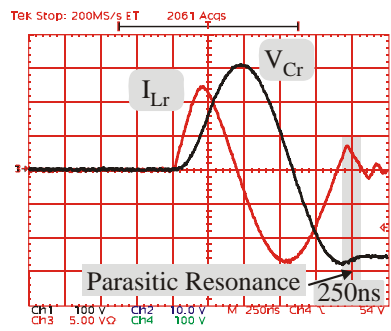

(b)

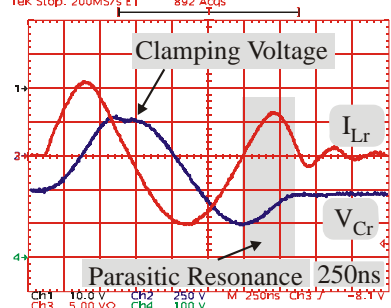

(d)
Fig. 18 - Experimental Waveforms for the Auxiliary

Elements. (a) (Tseng and Chen, 1998) (b) (Smith and Smedley, 1997); (c) (Xu et alii, 2000); (d) (Yang and Lee, 1993). $\mathrm{V}_{\mathrm{GS}}-10 \mathrm{~V} /$ div.; $\mathrm{V}_{\mathrm{DS}}-200 \mathrm{~V} /$ div.; $\mathrm{V}_{\mathrm{Cr}}-250 \mathrm{~V} / \mathrm{div}$; $\mathrm{I}_{\mathrm{La}}-5$ A/div.; Time 250 ns/div.

maximum positive value. In the same way, Fig. 18(d) shows the waveforms of the resonant tank elements for the ZVT PWM converters with Resonant AVS and clamping circuit presented in (Yang and Lee, 1993). Comparing the waveforms of Fig. 18(b), 18(c) and 18(d), it can be viewed that the reverse recovery current of the auxiliary switch anti-parallel diode and the forward voltage applied to its terminals initiate a parasitic resonant process that slightly discharge the resonant tank capacitor $\left(\mathrm{C}_{\mathrm{r}}\right)$. This discharge is more pronounced in Fig. 18(c) and 18(d) due to the higher forward voltage applied to the switch. It can result in a voltage unbalance across the auxiliary inductor $\left(\mathrm{L}_{\mathrm{r}}\right)$, which begins to conduct a residual current after the main switch turn-off, leading to a non-ZCS turn-on to auxiliary switch, Fig. 18(c). Thus, the auxiliary circuit conduction losses are increased due to the residual current and the auxiliary circuit switching losses are increased due to the non-ZCS turn-on. The waveforms presented in Fig. 18 were obtained from laboratory prototypes with the following specifications: $\mathrm{V}_{\mathrm{i}}=150 \mathrm{~V}_{\mathrm{DC}}, \mathrm{V}_{\mathrm{o}}=400 \mathrm{~V}_{\mathrm{DC}}, \mathrm{P}_{\mathrm{o}}=1 \mathrm{~kW}, \mathrm{f}_{\mathrm{sW}}$ $=100 \mathrm{kHz}$.

\section{SUMMARY}

Based on the concept of the auxiliary voltage source (AVS), which is required to control the power flow between the main and auxiliary circuit in soft-transition converters, a classification methodology of the ZVT converters is presented. By means of this concept, three classes of ZVT converters are identified. Moreover, the ZVT soft-switching mechanism is thoroughly explained 
and the elements required to accomplish the soft-switching conditions are recognized.

The converters that require an auxiliary pole to accomplish the ZVT conditions are classified as ZVT PWM converters with Switched AVS (Class A). These converters shift the turn-off problem from the main to the auxiliary switch. The large amount of different approaches utilized to alleviate the auxiliary switch turn-off problem generates the topologies that represent this ZVT Class. The mentioned auxiliary pole provides a simple and reliable means to accomplish the AVS demands for the ZVT PWM mechanism. Nevertheless, to overcome the commutation problems related to it, a set of additional components is included to the auxiliary circuit increasing its cost, complexity and introducing additional limitations.

On the other hand, in the ZVT PWM converters with DC AVS (Class B), a constant voltage source utilized to discharge the auxiliary inductor ensures ZCS conditions to the auxiliary switch. The different ways to implement this DC auxiliary voltage source generates the topologies that represent this ZVT class. The lowest reactive energy is the attractive of this class; however, the price paid for this is an increase in commutation interval. Moreover, in applications where the voltage source/sink is accessible and provides a time constant value, the realization of the AVS can result in a simple topology (ZVT PWM converters with DC AVS). On the other hand, the complexity added in the ZVT PWM converters with magnetically coupled DC AVS provides a extra degree of freedom that can be used to reduce the reactive energy and the current stresses of the auxiliary devices.

To overcome the constraints presented by class A (e.g., problems related to the auxiliary switch turn-off) and class B (e.g., practical implementation problems of the AVS) converters, in the ZVT PWM converters with Resonant AVS (Class $C$ ) a resonant tank plays the role of AVS to achieve ZCS to the auxiliary switch. In this case, the reactive energy associated with the resonant tank produces over current through the main switch and additional conduction losses. Moreover, the commutation interval is strongly dependent of the resonant tank frequency.

The choice of one ZVT topology is a question that depends on the application of the converter and also the requisites imposed to it. For instance, if simplicity is of prime concern, the ZVT PWM converters with DC AVS (Class B) will provide a good trade-off between efficiency and simplicity. However, due to the limitations imposed to the value of the DC AVS, in applications where the voltage conversion ratio of the converter varies in a wide range of values, such as PFC, it may not be a good choice to use a converter voltage source/sink as AVS. In this case, the ZVT
PWM converters with switched AVS snubber assisted may be a better choice.

The classification methodology presented is a useful tool to aid the design engineer in the identification and choice of the ZVT topology more suitable for a given application.

The investigation presented in this paper, provides a concise analysis about the ZVT soft-switching technique covering the mechanisms to achieve the soft-switching conditions. Moreover, it classifies the similar ZVT converters according to the way that the auxiliary voltage source is implemented, which can be used as an instrument to the synthesis of novel ZVT topologies.

\section{ACKNOWLEDGMENT}

The authors would like to express their gratitude to "Conselho Nacional de Desenvolvimento Científico e Tecnológico - CNPq” (proc. 308865/2003-0 and proc. 141914/2003-3) and "Coordenação de Aperfeiçoamento de Pessoal de Ensino Superior - CAPES” for financial support, Icotron - an EPCOS Company, Toshiba of Brazil and Thornton Inpec Eletrônica Ltda for material support.

\section{REFERENCES}

Ba-Thunya, A.S.; Pillai, S.K.; Prasad, D. (1998), “Some Novel Topologies of Soft-Switched Quasi-Resonant DC/DC Converters with Minimum Voltage Stress Across the Switch”, IECON 98, Vol. 1, p. 325-330.

Bazinet, J., O’Connor, J. A. (1994), “Analysis and Design of a Zero Voltage Transition Power Factor Correction Circuit" in IEEE Proc. of The 9th Annual Applied Power Electronics Conference and Exposition, APEC'94, p. 591-597.

Bodur, H., Bakan, A. F. (2002), “A New ZVT-PWM DCDC Converter”, in IEEE Trans. On Power Electronics, Vol. 17, No. 1, January 2002, p. 40-47.

Erickson, R.W.; Hernandez, A.F.; Witulski, A.F.; Xu, R. (1989), “A Nonlinear Resonant Switch”, IEEE Trans. on Power Electronics, Vol. 4, No. 2, p. 242-252.

Filho, N. P., Farias, V. J., Freitas, L. C. (1994), “A Novel Family of DC-DC PWM Converters Using the SelfResonance Principle", in IEEE Proc. of The 25th Annual Power Electronics Specialists Conference, PESC'95, p. 1385-1391.

Freitas, L. C., Cruz, D. F., Farias, V. J. (1993), “A Novel ZCS-ZVS-PWM DC-DC Buck Converter for High Power and High Switching Frequency: Analysis, Simulation and Experimental Results", in IEEE Proc. Of the 8th Annual Applied Power Electronics Conference and Exposition, p. 693-699. 
Gegner, J. P., Lee, C. Q. (1994a), “Zero-Voltage-Transition Converters Using a Simple Magnetic Feedback Technique", in IEEE Proc. of The 25th Annual Power Electronics Specialists Conference, PESC'94, p. 590596.

Gegner, J. P., Lee, C.Q. (1994b), “Zero-Voltage-Transition Converters Using an Inductor Feedback Technique”, in IEEE Proc. of The 9th Annual Applied Power Electronics Conference and Exposition, APEC'94, Vol.2, p. 862-868.

Gurunathan, R.; Bhat, A.K.S. (2001), ZVT Boost Converter Using a ZCS Auxiliary Circuit, Aerospace and Electronic Systems, IEEE Transactions on, Volume: 37, Issue: 3, July 2001, Pages:889 - 897.

Hey, Hélio Leães; Pinheiro, José Renes (1996). An Active Auxiliary Commutation Circuit for Inverters. In: 27TH IEEE Power Electronics Specialists Conference PESC'96. Piscataway: IEEE Press, 1996. v. 1, p. 223229;

Hua, G., Leu, C.-S., Lee, F. C. (1992), Novel Zero-VoltageTransition PWM Converters, in IEEE Power Electronics Specialists Conference, p. 55-60.

Hua, G., Leu, C.-S., Lee, F. C. (1995), Soft-Switching Techniques in PWM Converters, in IEEE Trans. On Industrial Electronics, Vol. 42, Issue 6, p. 595-603.

Hua,. G., Leu, C. S., Lee, F. C. (1991), Novel ZeroVoltage-Transition PWM Converters in VPEC, p. 8188.

International Rectifier Application Notes, IGBT or MOSFET: Choose Wisely, by Carl Blake and Chris Bull, International Rectifier.

Irie, H. (1991), Resonant Switches in Common Equivalent Circuit of DC/DC Converters, in IEEJ International Power Electronics Conference IPEC, p. 362-368;

Jain, N., Jain, P., Joós, G. (2001), “Analysis of a Zero Voltage Transition Boost Converter using a Soft Switching Auxiliary Circuit with Reduced Conduction Losses", in IEEE Proc. of The 32nd Annual Power Electronics Specialists Conference, PESC'01, Vol. 4, p. 1799-1804.

Kim, J.-H., Lee, D. Y., Choi, H. S., Cho, B. H. (2001), High Performance Boost PFP (Power Factor Preregulator) with an Improved ZVT (Zero Voltage Transition) converter, in IEEE Proc. of The 16th Annual Applied Power Electronics Conference and Exposition, APEC’01, Vol. 1, p. 337-342.

Kim, T.-W., Kim, H. -S., Ahn, H. -W. (2000), An Improved ZVT PWM Boost Converter, in IEEE Proc. of The 31st Annual Power Electronics Specialists Conference, PESC’00, Vol. 2, p. 615-619.
Kim, Y. -H., Kim, Y. -B., Cho, Y.-H (1998), A High Performance ZVT-PWM Boost Rectifier with Soft Switched Auxiliary Switch, in IEEE Proc. of the 24th Industrial Electronics Society Annual Conference, IECON'98, Vol. 2, p. 798-801.

Lee, F. C., Oruganti, R., Liu, K. H. (1985), Resonant Switches - Topologies and Characteristics in IEEE Power Electronics Specialists Conference, pp. 106116.

Lee, F. C., Lin, R. L., Y.Zhao (1998), Improved SoftSwitching ZVT Converters with Active Snubber, in IEEE Proc. of The 13th Annual Applied Power Electronics Conference and Exposition, APEC'98, Vol. 2, p. 1063-1069.

Lee, H. -O., Lee, D. Y., Cho, B. H. (2002), Improved ZeroVoltage-Transition (ZVT) Boost Converter using Coupled Inductor and Low-Voltage Zener Diode, in IEEE Proc. of the Power Conversion Conference, PCC-Osaka 2002, Vol. 2, p. 627-631.

Liu, H. -F., Liu, Y. -H., Tzou, Y. -Y. (2000), Implementation of ZVT Soft Switching Techniques in a Single-Phase PFC Rectifier for Server Power Supply, in IEEE Proc. of the 3rd International Power Electronics and Motion Control Conference, PIEMC 2000, Vol. 2, p. 584-589.

Liu, K.-H., Lee, F. C. (1988), Topological Constraints On Basic PWM Converters, IEEE PESC, p. 164-172.

Martins, D. C., Seixas, F. J., Barbi, I., Brilhante, J. A. (1993), A Family of DC-to-DC PWM Converters Using a New ZVS Commutation Cell, in IEEE Proc. of The 24th Annual Power Electronics Specialists Conference, PESC'93, p. 524-530.

Martins, M. L. S., Hey, H. L., Pinheiro, J. R., Pinheiro, H. and Gründling, H. (2001), Improved ZVT PWM Converters Using an Auxiliary Resonant Source in The 6th Brazilian Power Electronics Conference COBEP'01, p. 680-688; 458-463.

Martins, M. L. S., Hey, H. L., Pinheiro, J. R., Pinheiro, H. and Gründling, H. (2002), A ZVT PWM Boost Converter Using an Auxiliary Resonant Source in Applied Power Electronics Conference and Exposition, APEC 2002. 17th Annual IEEE , Vol. 2,p.1101-1107.

Menegáz, P. J. M., Có, M. A., Simonetti, D. S. L., Vieira, J. L. F. (1999), Improving the Operation of ZVT DC-DC Converters, in IEEE Proc. of The 30th Annual Power Electronics Specialists Conference, PESC'99, p. 293297.

Moschopoulos, G., Jain, P., Joos, G. (1995), A Novel ZeroVoltage Switched PWM Boost Converter, in IEEE 
Proc. of The 26th Annual Power Electronics Specialists Conference, PESC'95, p. 694-700.

Moschopoulos, G., Jain, P., Joos, G., Liu, Y.-F. (1996), A Zero-Voltage Switched PWM Boost Converter With An Energy Feedforward Auxiliary Circuit, in IEEE Proc. of The 27th Annual Power Electronics Specialists Conference, PESC'96, p. 76-82.

Prado, R. N. (1994), A New ZVT PWM Converter Family: Analysis, Simulation and Experimental Results in IEEE Proc. Of the 9th Annual Applied Power Electronics Conference and Exposition, APEC'94, Vol. 2, p. 978-983.

Russi, J., Martins, M.L., Grundling, H.A., Pinhetro, H., Pinheiro, J.R., Hey, H.L. (2003), A design criterion to ZVT DC-DC PWM converters with Constant Auxiliary Voltage Source, in Industrial Electronics, 2003. ISIE '03. 2003 IEEE International Symposium on, Vol. 1, June 9-11, p. 527-532.

Smith, K. M., and Smedley, K. M. (1997), A Comparison of Voltage-Mode Soft-Switching Methods for PWM Converters, IEEE Trans. on Power Electronics, Vol. 12, No. 2, March 1997, p. 376-386;

Streit, R., Tollik, D. (1991), A High Efficiency Telecom Rectifier Using A Novel Soft-Switched Boost-Based Input Current Shaper, in INTELEC, p. 720-726.

Tseng, C.-J., Chen, C.-L. (1998), Novel ZVT-PWM Converters With Active Snubbers, in IEEE Trans. on Power Electronics, Vol. 13, n. 5, p. 861-869.

Vlatkovic, V.; Borojevic, D.; Lee, F.C. (1994) Softtransition three-phase PWM conversion technology, in Power Electronics Specialists Conference, PESC '94 Record., 25th Annual IEEE, 20-25 June 1994, p. 79-84, Vol. 1.

W. McMurray (1964), SCR Inverter Commutated by an Auxiliary Impulse, in IEEE Trans. on Communications and Electronics, Vol 8-75, pp. 824-829, Nov/Dec.

Xu, D. M., Zhang, J. M., Ren, Y. C., Qian, Z. (2000), A Novel Single-Phase Active-Clamped ZVT-PWM PFC Converter, in IEEE Proc. of The 15th Annual Applied Power Electronics Conference and Exposition, APEC'00, p. 456-459.

Yaakov, S. B., Ivensky, G., Levitin, O., Treiner, A. (1995), Optimization of the Auxiliary Switch Components in a Flying Capacitor ZVS PWM Converters, in IEEE Proc. of The 8th Electrical and Electronics Engineers in Israel Convention, p. 5.4.4/1-5.4.4/5.

Yang, L., Lee, C. Q. (1993), Analysis and Design of Boost Zero-Voltage-Transition PWM Converter, in IEEE Proc. of The 8th Annual Applied Power Electronics Conference and Exposition, APEC'93, p. 707-713. 